\title{
El encuentro con dios. La conversión de aymaras al pentecostalismo en contextos de pluralismo médico
}

\author{
The Encounter with God. The Aymaras' Conversion to \\ Pentecostalism in contexts of Medical Pluralism
}

\author{
Carlos Piñones Rivera ${ }^{1}$ \\ Universidad Arturo Prat \\ Miguel Ángel Mansilla² \\ Universidad Arturo Prat \\ Rodrigo Galdames del Solar ${ }^{3}$ \\ Universidad de Tarapacá
}

\section{RESUMEN}

Este artículo expone nuestro análisis de la experiencia de sujetos aymaras convertidos al pentecostalismo en un contexto de pluralismo médico en Chile. Nos basamos en testimonios obtenidos a partir de una etnografía con agricultores aymaras de la localidad de Camiña (Tarapacá, Chile), desde los cuales analizamos la conversión religiosa como proceso contextualizado en la disputa por la hegemonía existente entre los saberes médicos locales. A partir de ello ponemos en relieve la experiencia del encuentro con dios, que desde nuestra perspectiva teórica constituye un elemento central en el proceso de producción de certezas ideológicas. Concluimos cuestionando las definiciones de la conversión basadas en la idea de una mera ruptura, para definirla como un proceso de desplazamiento del principio hegemónico entre los saberes propios del pluralismo médico. La conversión supondría un proceso de interpelación que, a la vez que articula elementos identitarios no-pentecostales, exige la producción de una identidad de ruptura, generando un posicionamiento identitario en conflicto con el sentido común andino. Subrayamos que dicho posicionamiento no resta eficacia a los elementos propios del saber médico andino al interior del proceso saludenfermedad-atención, pero sí los negativiza bajo el calificativo de idolatría.

Palabras clave: Conversión religiosa; Pentecostalismo; Aymaras; Pluralismo médico.

\section{SUMMARY}

This article discusses our analysis of the experience of conversion to Pentecostalism in a context of medical pluralism in Chile. We rely on testimonies obtained from an ethnography with Aymara farmers in the town of Camiña (Tarapacá, Chile), from which we analyze religious conversion as a contextualized process in the dispute over the hegemony of local medical knowledge. We highlight the experience of the encounter with God which, from our theoretical per-

\footnotetext{
${ }^{1}$ Correo electrónico: carlospinonesrivera@gmail.com. ORCID iD: <https://orcid.org/0000-0002-4771-3345>.

${ }^{2}$ Correo electrónico: mansilla.miguel@gmail.com. ORCID iD: <https://orcid.org/0000-0001-5684-0787>. Autor correspondiente.

${ }^{3}$ Correo electrónico: galdamesdelsolar@gmail.com. ORCID iD: <https://orcid.org/0000-0003-4835-5305>.
} 
spective, is a central element in the process of production of ideological certainties. We conclude by questioning the definitions of conversion based on the idea of a mere rupture, to define it as a process of displacement of the hegemonic principle in the medical knowledge inherent in medical pluralism. Conversion would entail a process of interpellation which, while articulating non-Pentecostal identity elements, requires the production of an identity of rupture, generating an identity position in conflict with Andean common sense. We emphasize that this positioning does not cancel out the efficacy of Andean medical knowledge within the health-illness-care process, but does negativize it under the label of idolatry.

Keywords: Religious Conversion; Pentecostalism; Aymaras; Medical Pluralism.

\section{INTRODUCCIÓN: LA CONVERSIÓN ENTRE LOS AYMARAS CHILENOS}

Los estudios sobre conversión religiosa han alcanzado un desarrollo profuso en las últimas décadas (Buckser y Glazier 2003; Andrade 2004; Steigenga y Cleary 2007; Gooren 2010; Tobergte y Curtis 2013). La amplia bibliografía que existe respecto del problema refleja los múltiples ángulos disciplinarios y conceptuales desde los que se ha abordado el proceso (Gooren 2010; Introvigne 2010). A pesar de esta amplitud de sentidos, se ha planteado que la noción que está en el núcleo de dichas concepciones es la de un cambio radical (Snow y Machalek 1984). Como han desarrollado Carozzi y Frigerio (1994: 4), "la conversión ha sido generalmente explicada en términos de modificaciones en las creencias y la "visión del mundo", [por lo que] parece lógico suponer que dichas modificaciones necesariamente implicarán cambios en el repertorio de identidades sociales que el individuo se autoadjudica, y consecuentemente en el comportamiento del mismo, al menos en ciertos contextos de interacción".

En Latinoamérica, el proceso de conversión ha estado marcado por una fuerte expansión del protestantismo, siendo objeto de varios estudios (Stoll 1985 y 1990; Canales, Palma y Villela 1991; Cantón-Delgado 1998; Piedra 2005; Steigenga y Cleary 2007). En este campo, algunos autores han abordado la conversión de personas pertenecientes a los pueblos originarios (García-Ruiz 1992; Fortuny 1994; Marzal 1997; Guerrero 1998; Molinari 1998; Otis 1998; Andrade 2004; Tancara 2008; Rivera 2015), cuestión que resulta de especial interés en tanto aparentemente supone una ruptura con la identidad indígena previa (Snow y Machalek 1984; Introvigne 2010). Al respecto la bibliografía es concisa, y no se han realizado sistematizaciones de tanta envergadura, destacando los trabajos de Garma Navarro (2005) en México, de CantónDelgado (1996 y 1998) en Guatemala, de Carozzi y Frigerio (1994) en Argentina y de Rivière (2007) y Harris (2006) en Bolivia.

Para el caso chileno, el fenómeno de la conversión en pueblos originarios se ha investigado escasamente. Foerster (1989 y 2005) y Moulian (2012) lo hicieron en población mapuche, mientras que Guerrero (1992 y 1998), Van Kessel y Guerrero (1987) y Mansilla, Muñoz y Orellana (2014; Muñoz y Mansilla 2015) lo han hecho en población aymara.

En un esfuerzo por identificar nuevas y promisorias líneas a seguir en el estudio de la conversión, Gooren (2010) ha analizado los principales sesgos de estos estudios, entre los que se encuentran: los propios de las disciplinas que la abordan; los de género y de clase social; los introducidos por el tipo de religión predominante- 
mente considerada y los de edad. Compartimos el análisis de Gooren y entendemos que los mismos se encuentran en el caso específico de la conversión en pueblos originarios. No obstante, a los sesgos ya reseñados, queremos añadir uno que nuestro punto de partida teórico nos permitió reconocer y que proponemos llamar el sesgo del monismo médico. Nos referimos a que, en este ámbito de discusión, en general se han comprendido los problemas de salud desde un único punto de vista, sea el biomédico, el pentecostal o el andino. Así se ha invisibilizado que los procesos de conversión se relacionan con la búsqueda de atención a los problemas de salud, y que al darse éstos en contextos de pluralismo médico, participan de los procesos de articulaciones de dichos saberes en múltiples niveles y sentidos.

En lo que sigue buscaremos iluminar una interpretación que surge del proceso de conversión cuando es analizado desde la asunción sistemática del pluralismo médico. Para esto, retomaremos el problema desde el material conferido por testimonios pentecostales en los cuales se relata la experiencia del encuentro con dios. Nuestra tesis es que el encuentro con dios es un elemento central en el proceso de convicción sobre la ideología pentecostal, ya que constituye una experiencia que es hegemonizada por una determinada lectura de la realidad, confiriéndole un carácter sólido e imperativo (Gramsci 1986: 265) para el sentido común pentecostal, en el marco de la disputa propia de los saberes que conforman el pluralismo médico.

\section{METODOLOGÍA}

El material de campo en el cual se basa nuestro análisis es fruto del trabajo etnográfico realizado con los agricultores aymaras de Camiña en la región de Tarapacá (Chile) entre los años 2011 y 2012. Tales datos forman parte de una investigación mayor, cuyo objetivo fue describir y analizar los saberes médicos y sus procesos de articulación y configuración de relaciones de hegemonía/subalternidad (Piñones Rivera 2015).

El diseño metodológico se estructuró específicamente para conocer cada uno de estos saberes médicos. Primero, utilizamos la observación participante como técnica principal de recolección de información. Para obtener información sobre el saber andino se realizaron observaciones en el centro de atención Casa del Kollire (co-administrado por la Asociación Kollire y la Municipalidad), así como también en los hogares de algunos qullirinaja, yatirinaja ${ }^{4}$ o pacientes donde se realizaban las atenciones. Para el caso del saber pentecostal se asistió a las sesiones de culto y a las concentraciones pentecostales realizadas en la iglesia local, y se visitaron las casas de personas enfermas para observar las vigilias. En el caso del saber biomédico las observaciones se llevaron a cabo en la posta de atención rural. Finalmente, para co-

${ }^{4}$ La palabra qulliri significa 'persona con cualidad de curar' (García Choque 2005). En nuestro campo se utilizaba para referirse a las personas que saben principalmente del uso de hierbas, emplastos o problemas de huesos y nervios. A diferencia de esto, yatiri significa 'el que sabe' (Layme 2004) y su conocimiento especializado (si bien no restrictivo), es sobre los llamados "problemas espirituales": susto, agarradura, mal impuesto, etc. (Piñones Rivera 2015). Cfr. también Choque Mariño (2012). 
nocer el saber de autoatención se observó la convivencia cotidiana en los espacios domésticos. Los tópicos claves abordados fueron las prácticas de atención a los problemas de salud.

De manera complementaria se realizaron 68 entrevistas a representantes de los distintos saberes médicos 5 . Fueron entrevistados 10 representantes del saber andino, 13 del pentecostal, 7 del biomédico, 28 del de autoatención y 10 correspondientes a la categoría "otros informantes". Mientras que 14 personas declararon poseer una adscripción religiosa pentecostal, 8 eran adventistas, 42 católicas, 1 persona se definió como atea y 3 señalaron no tener adscripción religiosa. Del total de entrevistados, 35 corresponden a mujeres y 37 a hombres. De este total solo 2 tenían menos de 20 años, 16 tenían entre 20 y 40 años, 23 entre 40 y 60 años, y 31 más de 60 años. Los tópicos centrales de las entrevistas fueron las diversas enfermedades sufridas y conocidas, poniendo especial atención en sus procesos de desarrollo, causas y prácticas de atención.

De esta manera, mientras de la observación participante obteníamos información directa sobre las prácticas de atención correspondientes a cada saber, las entrevistas nos entregaban información sobre las representaciones asociadas. Esto nos permitió generar una interpretación sobre los elementos ideológicos característicos de los saberes médicos, así como de los procesos de articulaciones que se dan entre ellos.

La información fue sometida a un análisis comparativo inicial de las distintas características ideológicas de los saberes médicos. Luego se identificaron los fenómenos o procesos donde se evidenciaba la presencia de elementos del saber andino y del saber pentecostal operando en las representaciones y prácticas de los especialistas de los distintos saberes en cuestión. De este conjunto se seleccionaron aquellos que destacaban por su recurrencia, interés teórico o grado de significatividad por su participación en el proceso salud-enfermedad-atención local. Posteriormente se verificó que los fenómenos y procesos relatados no fueran excepcionales, sino que formaran parte de las prácticas cotidianas y el sentido común de los especialistas o legos. Por último, se analizaron los rasgos ideológicos que obstaculizaban y facilitaban las articulaciones entre los saberes médicos concretos, así como la contribución que estas articulaciones generaban en el posicionamiento hegemónico de un determinado saber. El análisis en general se realizó siguiendo los principios teórico-metodológicos de la antropología médica crítica, lo que nos permitió centrarnos en las articulaciones y transacciones entre saberes hegemónicos y subalternos ${ }^{6}$. En conjunto, las distintas etapas del análisis antes mencionadas y la permanente reflexión sobre los múltiples niveles involucrados, permitieron la necesaria triangulación metodológica.

\footnotetext{
${ }^{5}$ Si bien el autor principal ha realizado cursos de lengua aymara no domina en profundidad la lengua, por lo que todo el trabajo de campo fue realizado en castellano. Compartiendo que el dominio de la lengua constituye un elemento central en el estudio de los pueblos originarios, se ha documentado profusamente el problema de la pérdida de la lengua aymara entre los chilenos (Gundermann Kröll 1995-1996 y Gundermann, Vergara y Díaz 2011), lo que se ve reflejado también en Camiña donde la mayoría de las personas no utiliza la lengua aymara, y solo una fracción la comprende.

${ }^{6}$ Un análisis detallado de esta propuesta puede leerse en Menéndez (1997) y Ramírez Hita (2005).
} 


\section{EL CONTEXTO SOCIAL Y POLÍTICO DE LA REFLEXIÓN}

Las conversiones que aquí analizamos se sitúan en un contexto de expansión de la Iglesia Evangélica Pentecostal por el territorio de Tarapacá, que se inicia en 1957 con el trabajo del pastor Braulio Mamani (Van Kessel y Guerrero 1987; Guerrero 1992; Mansilla 2009a). Dicho proceso se vio favorecido por los desplazamientos de varios comuneros aymaras desde el altiplano hacia los pueblos precordilleranos y las ciudades costeras (de la región y aledañas), como resultado de la intersección de muchos factores. Entre ellos se cuenta un fuerte período de sequía que afectó el altiplano de Tarapacá, pero también los procesos de transformación económica que impuso la dictadura de Pinochet y que en la región se materializaron a través de la creación de la Zona Franca de Iquique, multiplicando los flujos comerciales transfronterizos con Bolivia y Perú (Gundermann Kröll 1998; Van Kessel 2003; Díaz y Tapia 2013). Camiña fue un punto de asentamiento para muchas personas del altiplano, principalmente del sector de Isluga, dando origen al cordón poblacional que hoy se conoce como Alto Camiña.

En el ámbito de la atención de los problemas de salud, la población de Camiña tuvo acceso a atención biomédica de manera estable alrededor de los años 70, en que se establece un punto de atención rural. Previo a esto, la atención estaba principalmente en manos de los representantes del saber médico andino (yatirinaja, qullirinaja, yerbateros, parteras). Así en los años 80 se configura un panorama de pluralismo médico que existe hasta hoy, en el cual coexisten los saberes médicos andinos con los pentecostales y biomédicos, articulados en el seno de los saberes de autoatención.

Las relaciones de fuerza entre dichos saberes se han configurado claramente hacia una hegemonía de la biomedicina, desde el despliegue de la política de salud intercultural, que a nivel nacional se inicia el año 1996. Dicha política está ideológicamente basada en un multiculturalismo neoliberal (Díaz Polanco 2007; Boccara y Bolados 2011), desplegando un imaginario de la horizontalidad que ha sido analizado como un instrumento de subordinación (Piñones, Mansilla y Arancibia 2017). Paralelo a dicho imaginario de la horizontalidad y a las políticas multiculturales de que hoy el Estado chileno hace gala, se refuerzan las políticas extractivistas que vulneran los derechos colectivos de las comunidades. Ante esta situación, varias comunidades de la región de Tarapacá se han opuesto, organizándose para la defensa territorial. Es en dicho marco de sufrimiento social (Kleinman, Das y Lock 1997), que se presentan muchos de los problemas de salud que están a la base de las experiencias de conversión que aquí tratamos de comprender. Si bien nuestro material de campo es amplio, y se basa en observación participante, así como en entrevistas y análisis documental, aquí preferimos presentar viñetas de las entrevistas realizadas, pues permiten captar directamente el universo discursivo de los camiñanos.

\section{NARRATIVAS DE CONVERSIÓN: LOS TESTIMONIOS PENTECOSTALES. ALGUNOS CASOS DE ARTICULACIONES}

\section{a) UNA CURA PENTECOSTAL DE LA ESQUIZOFRENIA}

Ch. J. es un joven de 30 años que nos relata su experiencia de padecimiento categorizada como una esquizofrenia por los diagnósticos biomédicos. El relato es 
interesante para pensar los procesos de conversión, pues la curación prodigada en el seno del pentecostalismo marca una transformación profunda respecto de los fundamentos ideológicos de la Iglesia Evangélica Pentecostal.

Para mí por ejemplo dios existe, esa es la base. Pero parte de ahí porque yo no creía en dios. Yo tuve que vivir un hecho bien trágico... a la edad de diecinueve o veinte años me enfermé de esquizofrenia y estuve en el psiquiátrico [Iquique]. Y yo, por ejemplo, mi papá fue al extremo porque era su hijo mayor, lolito, recién había terminado cuarto medio y estaba con toda la vida por delante y mi papá al verme en ese estado se acercó más a dios y viendo que en el hospital psiquiátrico estaba peor y peor, estaba mal, entonces prácticamente me mantenían sedado con pastillas (Ch. J., entrevista personal, 20 jul. 2012).

Ante esta situación, el padre hace un "acto de fe" y a pesar de que los médicos le manifestaron que no podía sacarle del hospital, él les señaló: "¿sabe qué? yo creo en un dios todopoderoso y él lo va a sanar y un día Ud. lo va a ver doctor”. Así, firmó un documento que le permitió sacarlo del recinto bajo su responsabilidad, lo llevó a Camiña e inició un proceso de cuidado en el espacio doméstico. ¿Cuáles fueron los cuidados que se le prodigaron sin contar con la supervisión de un especialista biomédico? Esto es lo que nos cuenta Ch. J.:

me sacaron de ese lugar y me trajeron en esas condiciones, me trajeron para acá y aquí me aplicaron un poco todo lo que ellos creían que me podía hacer bien como remedio, pero siempre poniendo a dios por delante. ¿Qué pasaba?, yo me tomaba un remedio o una yerba. Me decían, esto te puede hacer bien para calmarte, y mi papá en acto de fe lo ungía y me lo daba en el nombre del señor. Y después no habrán pasado seis meses y yo me recuperé totalmente... y de hecho después pasó ese año, volví a Iquique y empecé a estudiar y estudiaba en la universidad. O sea, si estaba enfermo de esquizofrenia no podía (Ch. J., entrevista personal, 20 jul. 2012).

Como vemos, con independencia del tratamiento utilizado (remedio casero o medicina de patente), lo fundamental era que este se diera "poniendo a dios por delante" y siempre ungiéndolo en un acto de fe. Esta unción de los tratamientos constituye una práctica de articulación de los saberes médicos, omnipresente en los casos de atención de padecimientos entre los pentecostales de Camiña ${ }^{7}$ Y Y es dicha práctica articulatoria la que se presenta como eficaz en el tratamiento: no solo un tratamiento de unción sobre la persona, sino una unción sobre un tratamiento de otro saber médico.

Las experiencias de sanación como las señaladas, constituyen obras de dios, desde la perspectiva pentecostal. Ellas tienen un lugar central en la experiencia de conversión, pues fundan la creencia en dios, como se muestra a continuación:

hasta esa fecha todavía dudaba... no creía en dios y dios me respondió con fecha y con todo, entonces yo quizás no he visto a dios en persona, porque muchos piensan que uno lo ve en persona... yo no lo he visto, pero he visto obra de dios y por eso creo. Entonces para mí todas esas enfermedades y todo eso... hay alguien, no estoy solo.

Y, por ejemplo, hoy en día puede haber esa enfermedad del cáncer, yo viendo experiencia de hermanos, viéndolos en lo que yo me sané y cuando ellos cuentan enfermedades de cáncer y tantas cosas, yo sí creo.

${ }^{7}$ En contraste con esta omnipresencia, el carácter articulatorio no aparece en general en las descripciones y análisis del saber médico pentecostal entre los aymaras de Chile. 
Muchas veces yo antes no creía o estaba vacilando, hoy día tú me ves como evangélico, son cosas que tiene que haber en esta vida. Son cosas, accidentes, problemas, no estamos exentos de eso, pero hay alguien que nos puede ayudar o solucionar. O de repente nos somete a problemas porque ¿para qué?, porque muchas veces uno empieza a vacilar en la fe, entonces pasa algo y "jah señor! verdad que tú me sanaste una vez, me hiciste esto, de nuevo" (Ch. J., entrevista personal, 20 jul. 2012).

Como observamos en este relato, la curación al interior de la Iglesia Evangélica Pentecostal es concebida como una obra divina, de la cual se obtiene una certeza respecto de la existencia de dios. Dicha certeza transforma también el sentido que se le da a la enfermedad.

-Y ahora que tú eres evangélico ¿lo ves de otra forma o igual no más?

-No... con respecto a la enfermedad no... la enfermedad en sí. Hoy día la enfermedad es un espíritu, un mal espíritu, que por equis motivo en este mundo están la enfermedad, en este mundo están las cosas, los peligros, los accidentes, tantas cosas ¿no cierto?, pero ahí está dios ahí para ayudarme, porque esa vez igual cuando los médicos no pudieron, dios hizo lo imposible (Ch. J., entrevista personal, 20 jul. 2012).

b) LA CAÍDA DE F. J.

F. J. sufrió una caída desde siete metros de altura mientras se encontraba techando la casa de su abuela.

Mi papá me dijo vamos a hacerle sombra a la abuelita, mi abuelita en su casa, no tenía sombra era así, una pirqa ${ }^{8}$ [...] entonces yo me subí arriba para clavar, estaba clavando tranquilo, entonces estaba en las últimas por terminar, y siento que alguien me empuja así, y me voy para abajo, al camino, como siete metros de altura... me caí de frente (F. J., entrevista personal, 20 jul. 2012).

A pesar de la gravedad de la caída y de la insistencia de los familiares que estaban con él, F. J. se resiste a que lo conduzcan a recibir atención biomédica.

Mi papá decía vamos al hospital y no... no, yo decía que el Señor me tenía que sanar, y miraba al cielo y decía "Señor tú me tienes que sanar" [...]. Estaba con el dolor en la mano [...] e igual como que confianza plena en dios si no... por eso dicen "pon tu confianza plena en mín si no no verás maravillas. Fue así el espíritu de dios, porque dios no puede bajar a la tierra, la tierra está llena de maldad, y por eso envía ángeles, entonces, y así fueron como dos horas de agonía. Pero nunca dije vamos al hospital, porque estaba acá no más el hospital, porque yo conozco que con suero y con calmante de cualquier tipo, te calma, te deja tranquilo, y no quería. Le pedía al señor no más (F. J., entrevista personal, 20 jul. 2012).

En ese contexto es que F. J. narra el modo en que un primo menor suyo, de tan solo 10 años de edad, fue "tomado" por dios como instrumento para realizar la sanidad.

-Ya y fue así, y voy y a él lo tomó [...], y empezó como alguien que realmente conocía la biblia... iy niño!, jsiendo niño como que la biblia se la sabía al revés y al derecho! Y dijo que realmente era un espíritu malo, e igual como dios tiene ángeles, yo creo que el demonio también debe tener sus ángeles igual.

${ }_{-¿ E l}$ espíritu malo fue el que te empujó?

\footnotetext{
${ }^{8}$ Construcción por apilamiento y ajuste de piedras.
} 
-Mmm [asiente] porque yo realmente sentí como que alguien te empujara, estando allá arriba, y la cantidad de trabajo que hice, y no me pasó nada. Entonces... ya y empezó a hablar como una persona que se sabe la biblia así y me pescó la mano, y yo dije 'no, la mano no', y sentía el dolor... no sentí nada, fue como un alivio que me empezó y me recorrió todo el cuerpo... y paró. Como que todo el dolor se lo llevó, todo y quedé bien... o sea igual quedó machucado el cuerpo, pero quedé bien y sentí... la movilidad del pie y todo eso, y como estaba tanto tiempo ahí, cuando uno tiene un golpe lo que se te junta es la orina y por decir, la feca, y uno la siente [...]. Pero cuando caí, veía que corría sangre, y ensució todo y veía todo rojo después no, así... y al día siguiente mi papá tenía que bajar al trabajo, entonces me llevó con él. Pero esa noche fue muy bonita, para mí porque por decir, yo me vi toda mi vida, entonces, como que me sanó, yo veía la herida... me va a quedar el medio tajo. O me va a demorar un mes en sanar... tres días.

-¿En tres días te cerró?

-Claro.

$-¿ \mathrm{Y}$ te echaste algo? ¿Te pusiste algo? ¿O no?

-Me puse la venda no más... como estaba abierto para que no se infectara, pero nada más - Ya...

-Cuando me la saqué ya estaba cerrado, estaba sanado, cicatrizado. En la noche ya se cayó (F. J., entrevista personal, 20 de Julio de 2012).

Esta experiencia es la que signa la conversión de F. J. al pentecostalismo:

y eso fue cuando ya me empecé a meter en las cosas del señor. Ahí empecé a pensar realmente una estrofa de la biblia: 'teme a dios porque hay que temer de él no temerle al diablo', nada, porque si dios está contigo ¿quién va a estar contra ti?

-Nadie ¿no?

-Y antes tú dices el diablo va a estar contra ti porque dios es bueno y el diablo es malo, pero si tú te pones a pensar si dios es con nosotros, ¿quién contra nosotros? Nadie. Si él es poderoso y por decir como dice la biblia, es soberano, él hace como quiere y él lo puede deshacer. Entonces son cosas que después ya fui empezando a ver eso... en la iglesia, y así pasó mi cambio, caminar más en el señor. Eso fue lo que me llevó a ver (F. J., entrevista personal, 20 jul. 2012).

\section{LA CONVERSIÓN Y LA CENTRALIDAD DE LA EXPERIENCIA DEL ENCUENTRO CON DIOS COMO PRODUCTORA DE CERTEZAS IDEOLÓGICAS}

Los testimonios aquí presentados nos permiten exponer algunos elementos que encontramos de manera generalizada en las experiencias del encuentro con dios en nuestro trabajo de campo. Como se observa, estas experiencias tienen un lugar central dentro de los testimonios de conversión. Nuestro esfuerzo teórico se orientará a situar que dicha centralidad no es solo discursiva, en el sentido de que organizaría un relato identitario (sensu Snow y Machalek 1984), sino que radica en cierto tipo de experiencia. Dicha experiencia, que la mayoría de las veces es de curación, presenta ciertos rasgos de excepcionalidad': son experiencias de curaciones de personas des-

${ }^{9}$ La literatura ha clasificado esto de distintas maneras. Para Rambo (1993) estas experiencias son catalizadores de procesos de conversión, dentro de las cuales están las experiencias místicas (experiencias cercanas a la muerte, enfermedad-sanación, protean selfhood, patología, apostasía, crisis estimuladas externamente). Dado que el planteamiento de Rambo es genérico, tendríamos que decir que en el caso del pentecostalismo y por las razones ideológicas aquí expresadas, toda 
ahuciadas por la biomedicina, sanaciones milagrosas de accidentes, mejoras inexplicables de la suerte luego de rachas de infortunio, operaciones al corazón producidas en el plano espiritual, etc. Notemos que el carácter excepcional de la experiencia es atribuido generalmente a las curaciones y no a la afección, pues esta es significada como ocurriendo con total normalidad. Asimismo, que tiene un fuerte sentido individual, pues si bien en la Iglesia Evangélica Pentecostal las experiencias en que dios se hace presente (llamadas manifestaciones) son colectivamente frecuentes, la obra que el señor hace en la vida de las personas, es un hito que sobresale dentro de las otras experiencias personales sobre la presencia de dios. Individuales y excepcionales, las experiencias de encuentro con dios son referidas como fundamento de un cambio radical y profundo en la identidad, que se expresa a través de metáforas como las del renacimiento o la nueva vida ${ }^{10}$. Dicho cambio en la identidad es correlativo al cambio en la concepción de la realidad: el mundo pasa a ser (con evidencia) un lugar donde lo central es la existencia de dios y el cuidado de la relación personal con él.

En el caso específico que analizamos de la conversión de aymaras al pentecostalismo, la identificación de las prácticas andinas como meras idolatrías exige el alejamiento y abandono de varias prácticas con el fin de avanzar en el camino del señor: las personas deben dejar de practicar los bailes, de cantar las canciones, de acudir al yatiri, tocar sus instrumentos y melodías (en efecto, en la Iglesia Evangélica Pentecostal no se tocan instrumentos, solo se usa la voz), etc. ${ }^{11}$. Pero además se transforma un elemento central en la experiencia de la religión, pues si bien antes se podía creer o no en la existencia de dios, luego de la experiencia del encuentro con dios se instala una certeza sobre su existencia. Y esta, a su vez, transforma la comprensión del proceso salud-enfermedad-atención al establecer tres certezas complementarias que pasamos a detallar:

a) La certeza respecto al medio en que ocurre la curación: una vez producido el encuentro con dios, la persona asume que toda eficacia es en última instancia espiritual. Primero porque se realiza en un plano espiritual, en tanto dimensión invisible y articulada con el mundo. En la concepción pentecostal lo espiritual es una dimensión invisible a la percepción mundana, pero experienciable a través de múltiples procesos de mediación, e incluso visible en la medida que el fiel desarrolle el don de visión espiritual, o sea elegido por dios como instrumento (Piñones Rivera 2015). Segundo, porque aun realizándose directamente en lo material, responde a un sentido que está definido en el plano espiritual (es un mensaje de dios, es su obra). De

cura es una experiencia mística pues tiene el valor de una obra y por lo mismo no se distingue de las "experiencias de enfermedad" (Rambo 1993).

${ }^{10}$ Esto ha sido el elemento empírico utilizado por las teorías de la conversión que la entienden como una ruptura. Por ejemplo, en el clásico estudio de Travisano (citado en Gooren 2010: 24) se señala: "Conversion involves the "complete disruption" of an older identity; "anything less signals alternation"”.

${ }^{11}$ El ideal pentecostal supone, por lo tanto, una expoliación de muchas de las prácticas y representaciones características del mundo andino, a pesar de lo cual las personas no dejan de definirse como aymaras. Esto lo expresó Ch. J. así: "lo que nosotros dejamos de lado es solo la religión, porque seguimos trabajando la tierra y vivimos en nuestro pueblo, pero solo que ahora no practicamos la religión católica». 
esta manera se constata una duplicación del orden material por el espiritual, y es en este último donde es situada la eficacia. Notemos que esto hace que toda la interpretación del proceso salud-enfermedad-atención adquiera además del matiz de excepcionalidad e individualidad, los de meta-mundanidad y sobre-naturalidad.

b) La certeza respecto del agente de toda curación: en todos los casos en que se produce una curación esta es atribuida al poder divino. De esta manera, toda eficacia es entendida de forma vicaria (Piñones Rivera 2015). Así, y según pudimos observar en otro caso, cuando una qulliri convertida al pentecostalismo era eficaz en su tratamiento de composición de huesos, se suponía que lo era en tanto ha puesto su trabajo "en los pies del señor". En efecto, aún si no lo hiciera, su don sería comprendido como una gracia dada por el señor, por lo que la eficacia de su quehacer sería interpretada como algo que, en última instancia, emana de la voluntad y poder divinos.

Nos parece que ambos aspectos no son sino dimensiones de una asunción más amplia propia de la comprensión pentecostal del proceso salud-enfermedad-atención, consistente en que toda enfermedad o curación siempre debe ser interpretada desde la matriz simbólica de la relación entre la persona y el dios pentecostal. Esto tensiona - y en casos excluye- la interpretación de la enfermedad como resultado de las relaciones de reciprocidad con las entidades territoriales, propias del saber médico de los yatirinaja, que es categorizada como práctica idolátrica (Piñones, Mansilla y Muñoz 2016). Lo mismo ocurre con aquella interpretación que concibe la enfermedad como mero resultado de un determinismo biológico (Martínez-Hernáez 2008), pues siempre es posible atribuir un carácter espiritual tanto a la etiología como a la eficacia.

En consecuencia, sostenemos que el encuentro con dios no se reduce a una experiencia en que la persona tome conocimiento de la existencia de la dimensión espiritual, o de la reduplicación de la eficacia humana por una eficacia divina, sino que, por su intermediación, se produce una transformación en la convicción sobre determinados elementos ideológicos de los que ya tenía conocimiento.

c) La certeza respecto de la condición para toda curación: dentro de la matriz simbólica de la relación entre la persona y dios, se entiende que la condición para toda curación es el establecimiento y compromiso íntimo de una promesa de fidelidad y obediencia a su palabra (cfr. el caso de F. J.), que prototípicamente asume la forma de una retribución: si me sanas me comprometo a ser tu fiel servidor ${ }^{12}$. Notemos que mientras la biomedicina o incluso el saber médico andino exigen a la persona dinero que muchas veces no tiene, la Iglesia Evangélica Pentecostal exige algo de lo que siempre puede disponer ${ }^{13}$. La ausencia de una barrera económica al acceso de aten-

${ }^{12}$ Lalive D’Epinay (1968: 248) remitía este esquema a la tradición de los santos curanderos: "Desde el punto de vista sociológico, la curación por la fe no tiene nada que ver con el sacramento católico, sino que se arraiga culturalmente en la tradición de los santos curanderos, tan numerosos en Chile, y tan imponentes para la fe popular. De igual modo que se hace un voto a un santo ("Si tú me sanas, yo haré tal cosa"), el enfermo propone un trato a Cristo: "Si tú me sanas, yo seré discípulo tuyo”. El pentecostalismo elimina la hagiolatría, pero conserva el esquema del proceso".

13 Aquí no queremos dar a entender que no haya circulación de dinero en todo el proceso, pues de hecho existe el diezmo. Nos referimos más bien a que la atención del problema de salud no tiene como condición el intercambio de dinero. Ni siquiera bajo la forma de una deuda económica a ser pagada con posterioridad. 
ción en salud parece relevante, sobre todo en un contexto de mercantilización neoliberal como el chileno.

Si en general la promesa de fidelidad está presente antes del encuentro con dios, dos cosas se transforman en dicha experiencia: primero, la mera creencia en dios se transforma en atribución de verdad por evidencia de su presencia y poder; segundo, la promesa deviene deuda. Consideramos que esta duplicidad de efectos constituye una dialéctica específica entre la promesa y la obra que contribuye a la producción de certezas ideológicas sobre el pentecostalismo.

Del conjunto de elementos comunes presentes en las experiencias de encuentro con dios, lo que nos parece más llamativo y digno de análisis teórico es justamente que estas se presentan como fundamento de la certeza en los tres puntos expuestos. Nos parece que esto constituye su aporte específico, pues mientras en la experiencia cotidiana de los fieles ya podían existir tanto la ligazón persona-dios como matriz interpretativa de las experiencias cotidianas, así como la asunción de una dimensión espiritual en la realidad y eficacia; previo a la realización de la obra, la existencia de dios se podía vivir perfectamente como una mera creencia, persistiendo la duda sobre su ajuste a la verdad. Como señala Ch. J.: "hasta esa fecha todavía dudaba... no creía en dios y dios me respondió con fecha y con todo, entonces yo quizás no he visto a dios en persona, porque muchos piensan que uno lo ve en persona... yo no lo he visto, pero he visto obra de dios y por eso creo".

Podríamos señalar que esta convicción sobre la existencia de dios en la vida personal constituye el producto más importante de estas experiencias de encuentro con dios. O, expresado de otra manera, que la certeza de que la ideología pentecostal enuncia la verdad sobre dios se construye en buena medida desde dichas experiencias de encuentro.

Como podemos constatar en estos relatos, la experiencia concreta de la realización de una obra divina en la vida de algunos camiñanos, constituye un punto de inflexión cuyo valor es subrayado explícitamente por los conversos. De allí que el encuentro con dios posea también una importancia teórica, pues nos permite comprender la conversión al interior de los procesos articulatorios que se dan en el marco del pluralismo médico. ¿Cómo podríamos conceptualizar dicha significatividad experiencial y teórica?

\section{LA CONVERSIÓN Y LA PRODUCCIÓN IDEOLÓGICA DE CERTEZA EN LA DISPUTA POR LA HEGEMONÍA EN EL PLURALISMO MÉDICO}

Nuestra aproximación teórico-metodológica propone que es posible iluminar nuevas dimensiones del proceso de conversión entre los pueblos originarios, si se le sitúa en el marco del pluralismo médico en que frecuentemente se produce. Esto supone interrogar cómo la conversión es producida por los procesos de articulación de los saberes médicos entendidos como ideologías, es decir, en tanto terrenos en los cuales los conjuntos sociales y los individuos toman conciencia de su posición en el espacio social (Mouffe 1991).

En esta línea, las articulaciones de saberes médicos pueden consistir en confrontaciones, colaboraciones, yuxtaposiciones, mezclas, etc., de dichos complejos 
ideológicos (Menéndez 1994). A través de las articulaciones, los distintos saberes médicos participan en el abordaje del proceso salud-enfermedad-atención disputándose su hegemonía. Pero dado que sus funciones no son solo terapéuticas, más allá de la posibilidad de curar está en cuestión la hegemonía sobre la definición de los sentidos, las prácticas, el control social, la normalización y la subjetivación asociadas al proceso salud-enfermedad-atención (Menéndez 1983, 1984, 2005a y 2005b). Así, la conversión se observa como un proceso en el cual se juega la hegemonía de todos estos aspectos. En ese momento de suspensión temporal, de apertura o de cuestionamiento de los sentidos establecidos que supone el proceso salud-enfermedad-atención, la realidad del pluralismo médico se activa concretamente como campo social (Bourdieu 1986). Los distintos saberes se disputan explícita o implícitamente la autoridad y legitimidad sobre todas estas funciones, por medio de lenguajes y procedimientos diagnósticos, terapéuticos, interpretativos, de atribución de eficacia, etc. Es decir, se produce una disputa de la hegemonía del proceso salud-enfermedad-atención, ya sea por la intervención de los especialistas médicos, por el trabajo mismo de elección que realizan los afectados en el seno de sus itinerarios terapéuticos, o más frecuentemente por la intervención de ambos (Ramírez Hita 2005).

Desde aquí, uno podría interrogarse por qué el proceso salud-enfermedad-atención es un terreno especialmente propicio para disputar la hegemonía. Consideramos que este es uno de los procesos privilegiados donde se producen sentidos ideológicos como certezas (Gramsci 1999). Para entender esto debemos recordar que desde una lógica gramsciana todo padecimiento convoca a los saberes médicos para su atención. Dichos saberes especifican concepciones y prácticas sobre la salud y la enfermedad, a la vez que vehiculizan una serie de supuestos ideológicos sobre el cuerpo, las emociones, lo social, la realidad, etc. (Menéndez 1994, 2003 y 2005b). En este contexto, todo resultado pragmático de un saber médico tiene el efecto de afirmar dichos supuestos ideológicos como verdades. Y en virtud de dicha operatividad pragmática su versión de la realidad aparece con carácter de evidencia.

En los casos aquí analizados, la obra produce tanto la certeza sobre la existencia de dios, de lo espiritual, así como de la promesa como condición de la curación. Ahora bien, para ser precisos tenemos que decir que el proceso es más complejo, pues la atención y resolución de los problemas de salud resulta de la articulación de distintos saberes médicos: no se da solo gracias a uno de ellos. Este es uno de los elementos que aporta la mirada relacional adoptada y el enfoque del problema propuesto en el marco del pluralismo médico. En lo que sigue exploraremos el valor heurístico de esta aproximación.

\section{VI.1. LA ATENCIÓN DE LA ENFERMEDAD COMO ARTICULACIÓN DE SABERES MÉDICOS}

En contextos de pluralismo médico, el sentido común en el cual se produce la eficacia terapéutica no se localiza en un único saber médico. Más bien resulta de la relación entre los saberes médicos, produciendo un nuevo sentido común, fragmentario, articulado y eficaz en tanto soporta y da sentido a las prácticas cotidianas (Gramsci 1986; Mouffe 1991). 
En los casos revisados, la significación del proceso salud-enfermedad-atención se puede generar inicialmente desde cualquiera de los saberes presentes en el pluralismo médico. Por ejemplo, cuando Ch. J. califica su padecimiento como esquizofrenia, está haciendo uso de una nosología biomédica. No obstante, como muestra su testimonio, la atención eficaz no se produce en las coordenadas del saber biomédico, sino en la del saber médico pentecostal. En todas estas situaciones estamos en presencia de la articulación de saberes médicos: mientras el saber biomédico contribuye con la categoría diagnóstica, el saber médico pentecostal va a contribuir con la dialéctica de la promesa y la obra, en tanto elemento ideológico que posibilita la eficacia. Notemos que la curación no se produce sin la contribución ideológica del saber biomédico, pues su diagnóstico es el que moviliza y orienta un proceso de búsqueda de curación, definiendo algunos de los parámetros del itinerario terapéutico. En esa articulación entre elementos del saber biomédico y del saber médico pentecostal, se produce el encuentro con dios como curación pentecostal de una afección de raigambre biomédica ${ }^{14}$.

En otro lugar (Piñones, Mansilla y Muñoz 2016) y considerando los casos en que el sentido común predominante de la persona frente al proceso salud-enfermedadatención es el del saber médico andino, hemos desarrollado cómo la atención médica pentecostal aprovecha su ausencia de nosología para ofrecerse como un saber válido frente a un padecimiento andino. Así, resignifica a las entidades ancestrales (mallkus, t'allas, vertientes, serenos, chullpas, etc.) como demoníacas y configura una experiencia de la enfermedad como resultado de un alejamiento del camino de dios (Piñones, Mansilla y Muñoz 2016).

De este modo, en el terreno de la articulación de saberes médicos, el saber médico pentecostal se posiciona cuestionando la legitimidad ideológica de otros saberes, a la vez que reafirma la propia, al menos por tres vías:

a) La Iglesia Evangélica Pentecostal establece un proceso de cuestionamiento de las asunciones del sentido común no-pentecostal a través del concepto evangélico de Mundo. En el sentido pentecostal, el Mundo representa todo aquello que aleja a la persona del camino de dios y es, por lo tanto, un potente símbolo en la disputa por la hegemonía de los sentidos del proceso salud-enfermedad-atención y de la vida en general. En efecto, el complejo ideológico Mundo no coincide con 'el conjunto de todo lo existente' (Real Academia Española 2014, s. v. mundo), pues ciertos de sus elementos, de manera selectiva, pueden devenir mediatizaciones extramundanas: son las manifestaciones, los instrumentos, los mensajes u obras de dios en este mundo.

Así, el concepto está íntimamente ligado al de diablo, ya que es el espacio de la tentación del maligno. Y así todos los elementos del saber médico andino que configuran la práctica del yatiri, en tanto mundanos, son significados como idolatrías al demonio (Piñones, Mansilla y Muñoz 2016), negando su verosimilitud al significarla como engaño o poder demoniaco. El mundo que se legitima desde la experiencia del

\footnotetext{
${ }^{14}$ Subrayemos que al plantearlo de esta manera evitamos y superamos el embrollo realista respecto de si efectivamente o en la realidad se ha producido la enfermedad biomédica. Para nosotros no existe enfermedad biomédica sino como parte de un proceso salud-enfermedad-atención en el cual justamente la condición de biomédica, andina o pentecostal es algo que está disputado en el terreno ideológico como parte de la producción de relaciones de hegemonía/subalternidad.
} 
encuentro con dios es, por tanto, un mundo en tensión, dirigido por una voluntad de depuración de todo elemento demoniaco, demostrando así el valor que el diablo tiene como símbolo hegemónico (Piñones, Mansilla y Muñoz 2016). De esta forma, la Iglesia Evangélica Pentecostal legitima íntimamente una determinada realidad a través de la crítica sistemática del sentido común orientado por el concepto de Mundo (Mansilla 2009b).

No obstante, no es este elemento de crítica el único que sostiene la disputa pentecostal por la hegemonía. También son fundamentales algunos elementos de afirmación de sus propios planteamientos ideológicos. En primer lugar, la Iglesia Evangélica Pentecostal ofrece respuestas pragmáticas que reafirman y protegen el saber médico y el sentido común pentecostal de los cuestionamientos que atacan sus supuestos ideológicos (Mansilla, Orellana y Piñones 2017). Coincidimos con Schütz en que aquí la eficacia pragmática detiene el proceso de cuestionamiento de los supuestos ideológicos que definen el sentido común (Schutz y Luckmann 2001). Al respecto, la amplitud de beneficios que obtienen los participantes de la Iglesia Evangélica Pentecostal en términos de bienes materiales, beneficios emocionales, inclusión en redes de apoyo, etc., confirman a través de su eficacia pragmática, que la lectura pentecostal es verdadera en tanto presenta un "encadenamiento de evidencias prácti$\mathrm{cas}^{15}$, desde la cual se redefine lo que es la realidad.

Pero también la Iglesia Evangélica Pentecostal ofrece un esquema interpretativo amplio que permite incluir las experiencias disruptoras, excepcionales y excluidas de los sentidos comunes previamente hegemonizados en la experiencia de los sujetos. Al respecto, las experiencias límites o ajenas a la lectura racional moderna que quedan en la categoría de excepciones o de fenómenos inexplicados, son directa y fácilmente explicables por la Iglesia Evangélica Pentecostal acudiendo a un único esquema interpretativo básico, que entiende todo lo excepcional refiriéndolo a la dimensión espiritual y a la agencia divina.

A través de estos tres elementos, la Iglesia Evangélica Pentecostal participa de la disputa por la hegemonía, produciendo una deslegitimación sistemática de los otros saberes médicos, una apropiación de los elementos de eficacia presentes en ellos y aportando con claves interpretativas que, a la vez que incorporan evidencias prácticas a favor de sus supuestos ideológicos, permiten explicar experiencias que frecuentemente forman parte del proceso salud-enfermedad-atención como experiencias límites.

\section{VI.2. LA CONVERSIÓN COMO DESPLAZAMIENTO DEL PRINCIPIO HEGEMÓNICO}

Vistos los elementos del cuestionamiento de la legitimidad ideológica de los otros saberes que se realiza al interior de la Iglesia Evangélica Pentecostal, y afirmado el carácter articulatorio del horizonte en que se produce la eficacia terapéutica, corresponde desmarcarse de una teorización de la conversión como proceso monádico de

\footnotetext{
${ }^{15}$ En esta expresión parafraseamos la idea de Schütz (2001: 30): "La sucesión de experiencias, en la actitud natural, constituye típicamente una cadena de evidencias. Ahora bien; la cuestión que debemos examinar es cómo se interrumpe esa sucesión rutinaria de experiencias no problemáticas, y cómo surge un problema contra un fondo de evidencias".
} 
la ideología pentecostal. Lo entenderemos más bien como un proceso que se juega en el horizonte de un sentido común constituido por la articulación de los saberes propios del pluralismo médico.

Proponemos concebir la conversión entonces como un proceso de desplazamiento del principio hegemónico desarrollado en el juego de las relaciones articulatorias del pluralismo médico. El término principio hegemónico presente en Gramsci, sobre todo en El materialismo bistórico y la filosofía de Benedetto Croce (1971), ha sido realzado en el planteamiento de Mouffe (1991), para quien una visión del mundo incluye elementos heterogéneos, pero su unidad deriva de su principio articulador:

En consecuencia, la dirección intelectual y moral que una clase fundamental ejerce en un sistema hegemónico consiste en suministrar el principio articulador de la visión unitaria del mundo, el sistema de valores al cual se articularán los elementos ideológicos procedentes de los otros grupos, para formar un sistema ideológico unificado (Mouffe 1991: 212).

El desplazamiento del principio hegemónico no sería definitivo, pues está sometido a las relaciones de fuerza que configuran las hegemonías, pero tampoco es aleatorio, pues se define en las coordenadas ideológicas de su disputa, desarrollada en el terreno concreto del sentido común. Así concebida, la conversión no contempla ruptura, sino un desplazamiento de la hegemonía en un complejo articulatorio de saberes coexistentes. Esta hegemonía produciría una convulsión profunda de la dirección moral, intelectual y política de la vida del converso, pues en el proceso de atención aparece con carácter de evidencia, una realidad experimentada de manera acorde a la ideología pentecostal.

Esto se observa claramente en los casos de conversión aymara al pentecostalismo, donde la atención a los padecimientos está inicialmente definida en los parámetros del saber médico andino, pero la sanación es encontrada en el saber médico pentecostal a través de una serie de prácticas como la imposición de manos, la oración o las operaciones realizadas por los instrumentos, como mediación en el espíritu de la agencia divina (Piñones, Mansilla y Muñoz 2016). Entre uno y otro extremo se ha producido el encuentro con dios, una experiencia donde la reticencia que el sentido común andino había establecido respecto del pentecostal como saber proscrito (Carozzi y Frigerio 1994), se diluye y deviene convicción y certeza respecto del mundo pentecostal legitimado. Inversamente, a través del proceso de deslegitimación conducido por medio del concepto de $M u n d o$, se produce una subordinación de la ideología del saber médico andino al del saber médico pentecostal. El establecimiento de la relación de hegemonía/ subalternidad supone, como se observa, que lejos de desaparecer, el elemento andino permanece subordinado, pero en tensión, como parte del sentido común y del horizonte que estructura el proceso salud-enfermedad-atención y la lectura de la realidad. Mismo horizonte en el cual se produce la eficacia de las prácticas de atención.

En el caso de Ch. J., si bien el diagnóstico inicial se realiza dentro del saber biomédico, es el saber médico pentecostal el que a través de la cooptación de la eficacia articulatoria se hace con la hegemonía. Dicho proceso puede entenderse como un desplazamiento del principio hegemónico antes que como la incorporación de unos nuevos sentidos ideológicos, pues se realiza respecto de elementos ideológicos ya presentes, pero que no habían tenido dicha función de control moral, intelectual y político. 


\section{VI.3. UNA REINTERPRETACIÓN DE LA RUPTURA IDENTITARIA}

Teniendo en mano estos nuevos elementos teóricos, ¿cómo podemos interpretar la supuesta ruptura de la identidad? El carácter articulatorio del proceso de conversión, según venimos desarrollando, impide teorizar el proceso identitario solo como una ruptura. La imagen que se nos ofrece más bien es la de un proceso que ocurre al menos en dos niveles: en un nivel, la Iglesia Evangélica Pentecostal es capaz de articular elementos heterogéneos, pentecostales y no-pentecostales (música, vestidos, símbolos nacionales, creencias políticas, identidades barriales, símbolos de clase), que son constitutivos de la experiencia y de la producción de la identidad. Como hemos mostrado, es en virtud de esta capacidad articulatoria que se producen muchas de las experiencias del encuentro con dios; en otro nivel, no obstante, se produce una identidad basada en el quiebre, la ruptura y la desarticulación, en tanto la persona reescribe su biografía en términos de un esquema central de interpretación (Snow y Machalek 1984) que es la matriz simbólica persona-dios.

Si la Iglesia Evangélica Pentecostal deviene hegemónica es porque ha sido capaz de instituirse como directora de la vida social, estableciendo un principio hegemónico al interior de los procesos articulatorios que son por definición conformados por la heterogeneidad de saberes médicos y de ideologías ${ }^{16}$. Ahora bien, los quiebres identitarios se sostienen en la matriz simbólica de la relación persona-dios que constituye la roca firme desde la cual se produce el esfuerzo de desprendimiento imaginario de las otras identidades en el proceso de construcción del "self sagrado" (Csordas 1997). El proceso puede ser caracterizado como una interpelación ideológica que autoriza un campo en el que son posibles múltiples formas identitarias, siempre y cuando estén definidas en función de esta relación con dios. Además, esta relación debe estar en el centro de la vida, como dan cuenta los conocidos conceptos de «adopción de un esquema de atribución central" y "adopción de un rol central" (Snow y Machalek 1984). En virtud de la dialéctica de la promesa y la obra que ya hemos desarrollado, la deuda adquirida por el encuentro con dios produce una identidad como lealtad. Pero la reescritura de la identidad en términos de dicho esquema central de interpretación se entiende mejor cuando se observa como un proceso dentro de la disputa por la hegemonía, que como un rasgo intrínseco a una lógica discursiva monádica (Snow y Machalek 1984).

Comprender el proceso de conversión de los aymaras al pentecostalismo desde estas articulaciones, nos permite visualizar que la exigencia de univocidad en la definición identitaria propia del pentecostalismo, no suprime ni resta eficacia a los elementos ideológicos no-pentecostales (experiencias, recuerdos, sentidos, etc.). Por tanto, este esfuerzo rupturista, lejos de producir un "lavado de cerebro" (Carozzi y Frigerio 1994), genera un posicionamiento identitario en conflicto con el sentido común andino ${ }^{17}$

\footnotetext{
${ }^{16}$ Con esto no queremos desconocer la violencia que ha implicado históricamente el establecimiento de la ideología pentecostal (Guerrero 1982 y 1990; Stoll 1985 y 1990), solo iluminar uno de sus procesos ideológicos mejor establecidos.

${ }^{17}$ Cuando hablamos de sentido común andino no nos referimos sólo a la adscripción consciente a ciertos supuestos ideológicos, sino también a su incorporación y encarnación, es decir, aquello que Bourdieu (2007) conceptualizó como habitus. Así, la conversión religiosa no supone necesariamente la pérdida de autoidentificación étnica, pero sí un posicionamiento conflictivo en
} 
que, por ese mismo posicionamiento, perdura en la realidad social y personal negativizado como idolatría, en virtud del concepto de Mundo ya analizado. La coexistencia del sentido común andino-católico debe ser subrayada, pues juega un rol significativo en la configuración del proceso salud-enfermedad-atención, tanto en el plano de los diagnósticos, los procesos patogénicos, las causas, como los tratamientos, según hemos podido constatar.

\section{CONCLUSIÓN}

A partir de una perspectiva que discute lo que hemos llamado el sesgo del monismo médico, y que pone en relieve la relación del proceso de conversión con la búsqueda y necesidad de atención en el contexto del pluralismo médico, proponemos comprender la conversión de los aymaras al pentecostalismo desde los procesos de articulación de los saberes médicos entendidos como ideologías. Lo que queda en el centro de la interpretación teórica es, por tanto, el proceso de disputa por la hegemonía que se da entre los distintos saberes médicos en el marco de dicho pluralismo.

Esto nos abrió la posibilidad de analizar los procesos ideológicos por medio de los cuales el saber médico pentecostal participaba en dicha disputa. Vimos la función beligerante que adquiría el concepto de Mundo; también cómo la eficacia pragmática servía para afirmar los propios supuestos ideológicos; por último, analizamos la importancia de la provisión de un esquema interpretativo que permite integrar lo excepcional de muchos de los elementos de la experiencia propia del proceso saludenfermedad-atención.

Igualmente nos permitió situar a la experiencia del encuentro con dios como un elemento crucial de la producción de certezas ideológicas en el converso. A través de ella se establecería una triple certeza: sobre la existencia de dios, sobre el carácter espiritual de la eficacia terapéutica y sobre la promesa de fidelidad a dios como condición íntima para la eficacia de la sanación. Esta triple certeza contribuiría de manera fundamental al proceso de conversión, al producir el carácter sólido e imperativo para los elementos ideológicos pentecostales, desplazando el principio hegemónico desde los referentes andinos hacia los pentecostales y estableciendo una solución de continuidad en la experiencia del converso, que ellos expresan como el paso de la mera creencia en dios hacia la certeza de su existencia.

Así ofrecimos una reinterpretación del proceso de conversión que cuestiona la idea de una mera ruptura identitaria. La definimos entonces como un proceso de desplazamiento del principio hegemónico (Gramsci 1971) entre los saberes propios del pluralismo médico, que supone una interpelación que articula elementos identitarios nopentecostales, a la vez que exige la producción de una identidad de ruptura, generando un posicionamiento identitario en conflicto con el sentido común andino.

Subrayamos dicho conflicto ya que es un correlato, al interior del proceso de producción identitaria, de las relaciones de hegemonía/subalternidad en el espacio del

relación con el habitus andino. Este es uno de los elementos que sin duda se produce como resultado de la experiencia del encuentro con dios: un posicionamiento conflictivo en relación con el habitus andino previo. 
pluralismo médico. Respecto del proceso salud-enfermedad-atención, es importante subrayar que ni el posicionamiento identitario en conflicto, ni el desplazamiento del principio hegemónico, restan eficacia a los elementos propios del saber médico andino al interior del proceso salud-enfermedad-atención: éstos participan del proceso de articulación que genera nuevas formas de eficacia. Su influjo se observa más bien en la negativización que hace de los elementos andinos bajo el calificativo de idolatría.

Como se observa, todas estas nuevas perspectivas teóricas surgen de un esfuerzo inicial por abandonar el monismo médico y asumir de manera sistemática la complejidad que supone el pluralismo médico para pensar los procesos sociales que forman parte del proceso salud-enfermedad-atención. Consideramos que este esfuerzo debe ser profundizado, ya que en nuestro trabajo investigativo se ha constituido como una importante herramienta heurística.

\section{BIBLIOGRAFÍA CITADA}

Andrade, Susana. 2004. Protestantismo indigena. Procesos de conversión religiosa en la provincia de Chimborazo. Quito: Abya-Yala.

Boccara, Guillaume y Paola Bolados García. 2011. "¿Qué es el multiculturalismo? La nueva cuestión étnica en el Chile neoliberal". Revista de Indias 70(250): 651-690. doi: <https://doi.org/10.3989/ revindias.2010.021>.

Bourdieu, Pierre. 1990. Sociología y cultura. Martha Pou (trad.). México: Grijalbo.

Bourdieu, Pierre. 2007. El sentido práctico. Buenos Aires: Siglo XXI Editores.

Buckser, Andrew y Stephen D. Glazier. 2003. The Anthropology of Religious Conversion. Oxford: Rowman and Littlefield Publishers.

Canales, Manuel, Samuel Palma y Hugo Villela. 1991. En tierra extraña II: para una sociología de la religiosidad popular protestante. Santiago de Chile: Amerinda.

Cantón-Delgado, Manuela. 1996. "Curar y creer" en Guatemala: a la conversión religiosa (pentecostal) por la sanación física", en José González Alcantud y Salvador Rodríguez Becerra (eds.), Creer y curar: la medicina popular: 457-482. Granada: Diputación Provincial de Granada.

Cantón-Delgado, Manuela. 1998. Bautizados en fuego: protestantes, discursos de conversión y política en Guatemala (1989-1993). Guatemala: Centro de Investigaciones Regionales de Mesoamérica, CIRMA.

Carozzi, María Julia y Alejandro Frigerio. 1994. "Los estudios de la conversión a nuevos movimientos religiosos: perspectivas, métodos y hallazgos", en Alejandro Frigerio y María Julia Carozzi (comps.), El estudio científico de la religión a fines del siglo XX: 17-53. Buenos Aires: Centro Editor de América Latina, CEAL.

Choque Mariño, Carlos. 2012. Fortunato Manzano, el último yatiri. Vida, ritualidad, enseñanzas y religiosidad en Arica y Parinacota. [Arica]: Corporación Nacional de Desarrollo Indígena, CONADI/ Sucesión Fortunato Manzano.

Csordas, Thomas J. 1997. The Sacred Self: A Cultural Phenomenology of Charismatic Healing. Los Ángeles: University of California Press.

D'Epinay, Christian Lalive. 1968. El refugio de las masas: estudio sociológico del protestantismo chileno. Santiago de Chile: Editorial del Pacífico.

Díaz Araya, Alberto y Marcela Tapia Ladino. 2013. "Los aymaras del norte de Chile entre los siglos XIX y XX. Un recuento histórico". Atenea 507: 181-196. doi: <https://doi.org/10.4067/S0718$04622013000100012>$.

Díaz Polanco, Héctor. 2007. Elogio de la diversidad: globalización, multiculturalismo y etnofagia. México: Siglo XXI Editores.

Foerster, Roelf. 1989. "Identidad y pentecostalismo indígena en Chile». Creces 10(6): 12-18.

Foerster, Roelf. 2005. "Pentecostalismo mapuche: ¿fin o reformulación de la identidad étnica?». Disponible en: <http://repositoriodigital.uct.cl/handle/10925/126>. Fecha de acceso: 19 mar. 2014. 
Fortuny Loret de Mola, Patricia. 1994. "El pentecostalismo. Su capacidad de transformación en Jalisco y Yucatán". Nueva Antropología 13(45): 49-63. Disponible en: <www.redalyc.org/articulo.oa?id= 15904505>. Fecha de acceso: 15 sep. 2016.

García Choque, Pedro A. 2005. Aru Pirwa. Diccionario aymara-castellano y castellano-aymara. 3. ed. Iquique: Imprenta Graficolor.

García-Ruiz, Jesús. 1992. "De la identidad aceptada a la identidad elegida: el papel de lo religioso en la politización de las identificaciones étnicas en Guatemala". Transformaciones de la vida rural y poder local: 713-733. Número monográfico de la revista Estudios Sociológicos 10(30).

Garma Navarro, Carlos. 2005. "Conversión y los poderes de curación entre los protestantes totonacas". Revista Iztapalapa 12-13: 39-53.

Gooren, Henri. 2010. Religious Conversion and Disaffiliation. Tracing Patterns of Change in Faith Practices. Nueva York: Palgrave Macmillan.

Gramsci, Antonio. 1971. El materialismo bistórico y la filosofía de Benedetto Croce. Buenos Aires: Nueva Visión.

Gramsci, Antonio. 1986. Cuadernos de la cárcel, t. 4. Valentino Gerratana (ed.). México: Ediciones Era.

Guerrero, Bernardo. 1982. "La violencia pentecostal en la sociedad aymara". Cuaderno de Investigación Social 4: 34-44.

Guerrero, Bernardo. 1990. Las campanas del dolor: violencia y conflicto en los Andes chilenos. Iquique: Fundación Crear.

Guerrero, Bernardo. 1992. "Conversión y salud en el altiplano chileno". Revista de Ciencias Sociales 1: 30-36.

Guerrero, Bernardo. 1998. "La conversión al pentecostalismo. Una discusión teórica". Revista de Ciencias Sociales (CI) 8: 109-121. Disponible en: <www.redalyc.org/pdf/708/70800808.pdf>. Fecha de acceso: 9 ene. 2015.

Gundermann Kröll, Hans. 1995-1996. "Acerca de cómo los aymara aprendieron el castellano (terminando por olvidar el aymara)". Estudios Atacameños 12: 97-113.

Gundermann Kröll, Hans. 1998. "Pastoralismo andino y transformaciones en el norte de Chile". Estudios Atacameños 16: 293-319.

Gundermann Kröll, Hans, Jorge Iván Vergara y Alberto Díaz Araya. 2011. "Historia moderna de una lengua originaria: el Jaqi Aru en chile». RLA, Revista de Lingüística Teórica y Aplicada 49(1): 69-108. doi: <https://doi.org/10.4067/S0718-48832011000100005>. Fecha de acceso: 23 oct. 2012.

Harris, Olivia. 2006. "The Eternal Return of Conversion: Christianity as Contested Domain in Highland Bolivia", en Fenella Cannell (ed.), The Anthropology of Christianity: 51-76. Londres: Duke University Press.

Introvigne, Massimo. 2010. "El hecho de la conversión religiosa”. Scripta Theologica 42(2): $359-383$. Disponible en: <http://dadun.unav.edu/handle/10171/11679>. Fecha de acceso: 12 feb. 2014.

Kleinman, Arthur, Veena Das y Margaret M Lock. 1997. Social Suffering. Berkeley: University of California Press.

Layme, Félix. 2004. Diccionario bilingüe aymara-castellano. La Paz: Edición Consejo Educativo Aymara.

Mansilla, Miguel Ángel. 2009a. "Pentecostalismo y Ciencias Sociales: Reflexión en torno a las investigaciones del pentecostalismo chileno". Revista Cultura y religión 3(2). Disponible en: <https:// dialnet.unirioja.es/descarga/articulo/3088689.pdf>. Fecha de acceso: 19 mar. 2015.

Mansilla Agüero, Miguel Ángel. 2009b. La cruz y la esperanza: La cultura del pentecostalismo chileno en la primera mitad del siglo XX. Santiago de Chile: Editorial Universidad Bolivariana.

Mansilla, Miguel Ángel, Wilson Muñoz y Luis Orellana. 2014. "Los dilemas comunitarios y étnicos y religiosos: las investigaciones antropológicas del pentecostalismo aymara y mapuche en Chile (19672012)". Estudios Atacameños 49: 153-175. Disponible en: <http://www.scielo.cl/scielo.php?script= sci_arttext\&pid=S0718-10432014000300009>. Fecha de acceso: 18 sep. 2015.

Mansilla, Miguel Ángel, Luis Orellana y Carlos Piñones. 2017. "Las estrategias del pentecostalismo chileno frente a la pobreza. Un análisis del periodo 1909-1989". Anuario de Historia Regional y de las Fronteras 22(1): 49-70. doi: <https://doi.org/10.18273/revanu.v22n1-2017002>.

Martínez-Hernáez, Ángel. 2008. Antropología médica: teorías sobre la cultura, el poder y la enfermedad. Barcelona: Anthropos. 
Marzal, Manuel. 1997. "Conversión y resistencia de católicos populares del Perú a los nuevos movimientos religiosos", en Germán Medina, Religión y etnicidad en América Latina 3: 229-39. Bogotá: Instituto Colombiano de Antropología.

Menéndez, Eduardo Luis. 1983. Hacia una práctica médica alternativa: hegemonía y autoatención (gestión) en salud. México: Cuadernos de la Casa Chata/CIESAS.

Menéndez, Eduardo Luis. 1984. "Estructura y relaciones de clase y la función de los modelos médicos". Nueva Antropología 6(23): 71-102. Disponible en: <http://www.redalyc.org/articulo.oa?id=15902307>. Fecha de acceso: 12 feb. 2014.

Menéndez, Eduardo Luis. 1994. "La enfermedad y la curación ¿qué es medicina tradicional?”. Alteridades 4(7): 71-83. Disponible en: <http://www.redalyc.org/articulo.oa?id=74711357008>. Fecha de acceso: 10 jul. 2010.

Menéndez, Eduardo Luis. 1997. "El punto de vista del actor. Homogeneidad, diferencia e historicidad". Relaciones 69: 237-271. Disponible en: <http://www.colmich.edu.mx/relaciones25/files/revistas/ 069/EduardoLMenendez.pdf $>$. Fecha de acceso: 10 jul. 2010.

Menéndez, Eduardo Luis. 2003. "Modelos de atención de los padecimientos: de exclusiones teóricas y articulaciones prácticas". Ciência \& saúde coletiva 8(1): 185-207. doi: <https://doi.org/10.1590/ S1413-81232003000100014 >. Fecha de acceso: 10 jul. 2010.

Menéndez, Eduardo Luis. 2005a. "El modelo médico y la salud de los trabajadores". Salud Colectiva 1(1): 9-32. Disponible en: <http://www.redalyc.org/articulo.oa?id=73110102>. Fecha de acceso: 10 jul. 2010.

Menéndez, Eduardo Luis. 2005b. «Intencionalidad, experiencia y función: la articulación de los saberes médicos". Revista de Antropología Social 14: 33-69. Disponible en: <www.redalyc.org/pdf/838/ 83801402.pdf >. Fecha de acceso: 10 jul. 2010.

Molinari, Claudia. 1998. "Protestantismo y cambio religioso en la Tarahumara: apuntes para una teoría de la conversión", en Elio Masferrer K. (compilador), Sectas o iglesias. Viejos o nuevos movimientos religiosos: 191-205. México: Plaza y Valdés Editores.

Mouffe, Chantal. 1991. "Hegemonía e ideología en Gramsci", en Hernán Suarez, Antonio Gramsci y la realidad colombiana: 167-227. Bogotá: Foro Nacional por Colombia.

Moulian, Rodrigo. 2012. "Metamorfosis ritual. Desde el nguillatún al culto pentecostal. Teoría, historia y etnografía del cambio ritual en comunidades mapuche huilliche». Disponible en: <www.redalyc.org/ articulo.oa?id=45929109009>. Fecha de acceso: 12 sep. 2015.

Muñoz, Wilson y Miguel Ángel Mansilla. 2015. "Conflacionismo epistemológico: los estudios sobre el pentecostalismo aymara en Chile (1975-1998)". Revista Cinta de Moebio 52: 1-16. Disponible en: <http://www.facso.uchile.cl/publicaciones/moebio/52/munoz.html $>$. Fecha de acceso: 4 abr. 2016

Otis, George de. 1998. "Buscando "vida": Hechicería, curaciones por la fe y conversión religiosa entre los Huicholes", en Los evangelismos en México: 49-71. Número monográfico de la revista Religiones y sociedad 3 .

Piedra, Arturo. 2005. Evangelización protestante en América latina: análisis de las razones que justificaron y promovieron la expansión protestante 1830-1960, vol. 1. San José/Quito: Universidad Bíblica Latinoamericana/Consejo Latinoamericano de Iglesias.

Piñones Rivera, Carlos. 2015. La mala hora. Articulaciones en el pluralismo médico de agricultores precordilleranos aymaras chilenos. Tesis Doctoral. Universitat Rovira i Virgili.

Piñones Rivera, Carlos, Miguel Mansilla y Rodrigo Arancibia. 2017. «El imaginario de la horizontalidad como instrumento de subordinación: la Política de Salud pueblos indígenas en el multiculturalismo neoliberal chileno". Saúde e Sociedade 26(3): 751-763. doi: <https://doi.org/10.1590/s0104$12902017169802>$.

Piñones Rivera, Carlos, Miguel Mansilla y Wilson Muñoz. 2016. "La agarradura me la atiendo en la iglesia”: el diablo como símbolo hegemónico en el pluralismo médico aymara pentecostal. Chungará (Arica) 48(4): 645-656. doi: <https://doi.org/10.4067/S0717-73562016005000037>.

Rambo, Lewis R. 1993. Understanding Religious Conversion. New Haven/Londres: Yale University Press.

Ramírez Hita, Susana. 2005. Donde el viento llega cansado. Sistemas y prácticas de salud en la ciudad de Potosí. La Paz: Plural Editores.

Real Academia Española. 2014. Diccionario de la lengua española. 23. 
Rivera, Enrique. 2015. "Conversión religiosa e identidad cultural en el altiplano peruano". Cultura y religión 9(1): 51-63. Disponible en: <http://132.248.9.34/hevila/Culturayreligion/2015/vol9/no1/ 3.pdf>. Fecha de acceso: 15 sep. 2016.

Rivière, Gilles. 2007. "Bolivia: el pentecostalismo en la sociedad aimara del Altiplano". Nuevo Mundo Mundos Nuevos. Disponible en: <http://journals.openedition.org/nuevomundo/6661>. Fecha de acceso: 19 mar. 2015.

Schütz, Alfred y Thomas Luckmann. 2001. Las estructuras del mundo de la vida. Buenos Aires: Amorrortu.

Snow, David A. y Richard Machalek. 1984. "The Sociology of Conversion". Annual Review of Sociology 10: $167-190$.

Steigenga, Timothy y Edward L. Cleary. 2007. Conversion of a Continent: Contemporary Religious Change in Latin America. New Brunswick: Rutgers University Press.

Stoll, David. 1985. ¿Pescadores de hombres o fundadores de imperio? Flica Barclay (trad.). Lima: DESCO, Centro de Estudios y Promoción del Desarrollo.

Stoll, David. 1990. ¿América latina se vuelve protestante?: las políticas del crecimiento evangélico. Quito: Abya-Yala.

Tancara, Juan Jacobo. 2008. "Tuve una importante revelación": revelación en la experiencia evangelizadora andina”. Siwô'. Revista de teología 1: 179-216. Disponible en: <http:// www.revistas.una.ac.cr/index.php/siwo/article/view/847>. Fecha de acceso: 19 mar. 2014.

Tobergte, David R. y Shirley Curtis. 2013. Religious Conversion. Contemporary Practices and Controversies. Londres: Cassel.

Van Kessel, Juan. 2003. Holocausto al progreso. Los aymarás de Tarapacá. Iquique: Instituto para el Estudio de la Cultura y Tecnología Andina, IECTA.

Van Kessel, Juan y Bernardo Guerrero. 1987. Sanidad y salvación en el altiplano chileno: del yatiri al pastor. Iquique: Centro de Investigaciones de la Realidad del Norte, CIREN.

Fecha de recepción: 13 de enero de 2017

Fecha de aceptación: 23 de enero de 2018 